\title{
A SAÚDE DO MAGISTRADO: UM BREVE LEVANTAMENTO BIBLIOGRÁFICO
}

\author{
Cíntia Gonçalves Costi'
}

Resumo: Este artigo por meio de um levantamento bibliográfico aponta pesquisas relativas à saúde dos magistrados, no viés da complexidade da relação do homem com o trabalho, visto que tais relações têm levado os pesquisadores a investigar seus reflexos na saúde dos trabalhadores. As pesquisas revelam dados do trabalho dos juízes, principalmente, pela abordagem do estresse.

Palavras-chave: Saúde. Magistratura. Estresse.

\section{INTRODUÇÃO}

A complexa relação do homem com o trabalho pode ser considerada base fundamental para a organização e a estruturação da sociedade (Rocha \& Nunes, 1993). Um dos focos possíveis para análise do contexto em que o homem estabelece um vínculo efetivo com o trabalho, está presente na relação que este mantém com sua ocupação laboral, seus objetivos, sua qualidade de vida e sua saúde.

Para melhor entendimento dessa relação, é preciso compreender um dos contextos de gênese dessa relação: o trabalho. Licciardi (2011) apresenta o trabalho como um construto derivado da palavra "tripalium", que no latim fazia referência a um instrumento de tortura. Durante um vasto período, o trabalho esteve associado ao fardo e ao sacrifício.

Albornoz (1994) afirma que, a visão de que o trabalho poderia ser um agente importante na construção da identidade

1 Juíza de Direito em Santa Catarina. E-mail: cintiacosti@tjsc.jus.br 
do homem e que teria alguma relação com autorrealização e satisfação das necessidades e desejos humanos, é uma construção mais recente, nascida, aproximadamente, a partir do Renascimento. $\mathrm{O}$ trabalho, portanto, passa a ser entendido como um espaço de desenvolvimento e de transformação necessário para a construção da liberdade humana. Assim, seu significado é separado do âmbito do fardo, do sacrifício e da escravidão (Albornoz, 1994)

Ainda a respeito do trabalho, Codo (1999) apresenta uma possível definição de caráter produtivo, que amplia a visão de construção subjetiva para a formatação de um fator do trabalho, que é a transformação da natureza pela interferência de um homem, ou de vários deles. $\mathrm{O}$ autor apresenta o trabalho como um fator de mudança de um produto que fora antes natural e que permanece no tempo e espaço como outro objeto, que foi transformado pelo homem, no mesmo instante em que este mesmo homem fora transformado pelo produto do seu trabalho (Albornoz, 1994).

Freud (1907/1982) define saúde mental como a capacidade do homem em amar e trabalhar. Vasques-Menezes (2004), com base nessa definição, sustentam que a importância do trabalho na vida do homem é tão relevante quanto a sexualidade, reinvindicando sua inclusão na hierarquia de importância freudiana. Conclui-se, portanto, que o trabalho é vital ao homem, no que tange à higidez de sua saúde mental.

Com essas possíveis definições teóricas relativas ao contexto do trabalho, refletir acerca dos possíveis modos pelos quais a condição de vida pode ser afetada pela produção humana é inevitável. É fundamental que as intercorrências na qualidade de vida sejam levantadas e consideradas, pois o âmbito do trabalho, e suas características, podem vir a desencadear adoecimento no trabalhador, inclusive mental. Observa-se que o processo de automação do trabalho, principalmente a partir da década de 1960, pode ter diminuído a carga física para alguns trabalhadores, mas, em contrapartida, houve uma progressão sensível na exigência psíquica. Este processo é uma 
possivel gênese do aumento percebido da incidência de adoecimento psíquico laboral (Borsoi, 2007).

\subsection{Relações de trabalho e adoecimento psíquico}

Para uma compreensão ampliada das intercorrências do trabalho na constituição da saúde psíquica, é preciso maior entendimento do que seja a saúde mental humana. A constituição de uma doença mental, ou adoecimento psíquico, pode ser entendida pela equação entre a capacidade de resiliência ${ }^{2}$ de um homem e os eventos adversos que causam algum tipo de sofrimento psíquico. O sofrimento no âmbito psíquico pode ser caracterizado pela "dificuldade do sujeito em operar planos e definir sentidos para a vida, aliada a sentimento de impotência e vazio, o eu sendo experimentado como coisa alheia" (Sampaio \& Messias, 2002, p. 151). A doença mental pode ser entendida como:

um modo de reapropriação individual, que revela o fracasso das tentativas de entender, superar, evitar ou tornar suportável os sofrimentos psíquicos, radicalizando o processo de alienação e fazendo o sujeito viver tensões sem expectativa de solução ou abolir aparencialmente os pólos de tensão entre parte/todo, essência/aparência, indivíduo/ sociedade, consciência/objetividade (Sampaio \& Messias, 2002, p. 151).

$\mathrm{O}$ adoecimento mental, portanto, pode surgir como um fator de rompimento da capacidade do indivíduo em suportar o sofrimento psíquico e pode decorrer de vários aspectos e situações da vida, inclusive do trabalho.

Podemos nomear o sofrimento, ou adoecimento no contexto do trabalho, de adoecimento laboral. No contexto desse tipo de adoecimento, pesquisas demonstram que entre as doenças que afetam os trabalhadores nos setores público e

2 Pode ser entendida como a capacidade (física, biológica, política, social e psicológica) de enfrentamento a eventos que desafiam a possibilidade de sucesso e de transformação e fortalecimento subjetivo em experiências de adversidade (Soria, Blandtt e Ribeiro, 2007). 
privado, há prevalência dos transtornos mentais e comportamentais leves ou moderados (TMLM do CID-10³), também chamados de não-psicóticos (Santa Helena \& Lasagno,Vieira, 2010).

$\mathrm{O}$ adoecimento laboral atinge os trabalhadores em geral, tanto aquele com exigências físicas maiores, como aqueles de exigência intelectual, já que o mercado de trabalho cada vez mais demanda aumento da produtividade e do lucro em todas as áreas (Borsoi, 2007).

Apesar da referida prevalência, no que se refere à saúde mental, na sua aferição, medida e principalmente na sua origem e eventual nexo de causalidade com o trabalho, esbarra-se na dificuldade de quantificação, já que, diferentemente do adoecimento físico, o adoecimento mental não é palpável, "não é possível quantificar a vivência, que é em primeiro lugar qualitativa” (Dejours, 1994, p. 22). Mas, ainda assim, é possível constatar que como resultado do processo de transformação da realidade laboral, verifica-se o aumento no número de lesões e acidentes no local de trabalho e decorrentes dele, bem como dos transtornos mentais e comportamentais relacionados às atividades de labor e exigência demasiadas, com destaque para o estresse ${ }^{4}$, a depressão, a síndrome de burnout ${ }^{5}$, entre outros (Teixeira, 2007).

\subsubsection{O processo laboral do magistrado: demandas e fatores de risco}

O cotidiano e as demandas do trabalho do magistrado, assim como em outras profissões, são pouco conhecidos da

3 World Health Organization.(1993).Classificação de Transtornos Mentais e de Comportamento da CID-10. P. Alegre: Artes Médicas.

4 O estresse é uma alteração psicofisiológica do organismo com sintomas físicos e psicológicos, para reagir a uma situação de tensão e opressão. O estresse é um processo e não uma reação única, pois a partir do momento em que uma pessoa é submetida a uma fonte de estresse (Lipp, 1996).

5 A síndrome de Burnout pode ser definida como uma condição de comprometimento integral, ou parcial, relacionada à organização do trabalho. Essa configuração é uma reação crônica à tensão emocional produzida pelo contato estressante e excessivo com o contexto do trabalho, local, funções laborais e pessoas envolvidas no labor (M aslach \& Jackson, 1981, Maslach \& Leiter, 1997). 
sociedade. As funções, atividades e características hierárquicas da profissão são invisibilizadas frente à imagem do julgamento de um processo, faceta pública reconhecida. No entanto, o trabalho do juiz é caracterizado por normatizações e o exercício de atividades em contextos distintos, configurando a realização de múltiplas funções.

Além disso, a profissão é regulada por guias e códigos de conduta próprios(art. 92 e seguintes da Constituição Federal, Lei Orgânica da Magistratura Nacional - LOMAN, Lei Complementar n.035/1979 e nos regimentos inernos e códigos de normas dos tribunais). As regras ali dispostas incluem comportamentos no trabalho e na vida social, exigindo, no mínimo, imparcialidade, independência e integridade, já que a imagem e a reputação do juiz refletem a do Poder Judiciário.

No Brasil, a Lei Orgânica da Magistratura (art. 35), trata da matéria, determinando que o magistrado aja com independência, serenidade e exatidão em seu trabalho, trate com urbanidade as partes e demais atores do cenário judicial, e atenda aos que o procurarem, a qualquer momento, quando se trate de providência que reclame e possibilite solução de urgência, além de manter conduta irrepreensível na vida pública e particular.

As atribuições dos juízes podem ser divididas entre administrativas e jurisdicionais. No âmbito administrativo, cada juiz é responsável pela gestão da sua unidade jurisdicional, composta pelas equipes de gabinete e cartório. As funções administrativas compreendem desde a coordenação e gerenciamento de patrimônio e pessoal, à representação do Poder Judiciário em solenidades e questões de interesse público junto à comunidade ${ }^{6}$.

O juiz de direito, ainda, que é o juiz estadual, com competência residual, na função de juiz diretor do fórum, responsabiliza-se também pela correição ${ }^{7}$ dos cartórios extrajudiciais e de eventual unidade prisional sob sua jurisdição. É de responsabilidade do juiz de direito a jurisdição eleitoral, que consiste

6 De acordo com os arts. 109 e 110 do Código de Divisão e Organização Judiciária do Estado de Santa Catarina - CDOJESC

7 De acordo com os arts. 30 a 32 CDOJESC 
em coordenar as eleições, além de processar e julgar todas as questões judiciais resultantes do pleito.

Segundo o CNJ, os juízes brasileiros julgam 22 milhões de processos por ano, ou 100.000 sentenças por dia útil, o que, somados a todas as outras atividades listadas acima, demonstra em números a enorme produtividade do juiz brasileiro. (http:// www.espacovital.com.br/noticia-28949-sentenca-nao-em-arvoreartigo-jose-lucio-munhoz).

Na medida em que o juiz avança na carreira, quando promovido para comarcas maiores, com mais de uma vara, as funções de diretor do fórum, juiz corregedor de presídios e juiz eleitoral, são distribuídas entre os magistrados daquela comarca, de acordo com sua área de atuação e mediante revezamento periódico.

A atuação dos juízes no mundo ocidental é semelhante, cabendo-lhes o julgamento dos processos de acordo com a legislação de cada país. A atuação dos magistrados é direta com as partes nos processos criminais, cíveis e de família. Lidam diariamente com o sofrimento humano, pois, nas cortes de justiça desembocam os resultados das falhas dos sistemas político, econômico e social (Anleu \& Mack, 2005), fazendo com que as pessoas procurem no judiciário - e na pessoa do juiz - a última instância para solucionar seus problemas.

Apesar de outras profissões também se caracterizarem pela necessidade de tomada de decisões importantes, durante extensas jornadas de trabalho e muitas vezes expostos à violência - como nas profissões de policiais, médicos e professores -, na profissão do juiz existe uma combinação única dessas experiências, que pode ser excessivamente onerosa, como, por exemplo, a possibilidade de ver-se ameaçado por organizações criminosas, réus, condenados ou pessoas descontentes com a decisão tomada em determinada situação.

A fascinação pública que a profissão evoca, coloca o juiz sob constante escrutínio público (Resnick et al., 2011), especialmente quando as decisões clamorosas são acompanhadas de perto pela imprensa, fazendo com o que seu trabalho e sua vida passem a ser expostos pela mídia. 
A possibilidade de ver-se ameaçado é iminente na ocupação laboral do juiz e é uma das características de maior diferenciação frente às demais profissões. As exigências de interpretar a lei e de distribuir a justiça, aliadas ao sentimento constante de ameaça, são ocorrências que podem gerar um aumento no nível de estresse dos profissionais (Zimmerman, 1981 como citado em Lipp \& Tanganelli, 2002).

O levantamento dos construtos e fenômenos que serão apresentados e discutidos no presente artigo, tem como objetivo investigar a produção científica acerca do processo de adoecimento laboral dos magistrados, tendo em vista a caracterização das doenças mais frequentes.

\section{CARACTERIZAÇÃO DA PESQUISA BIBLIOGRÁFICA}

Para o levantamento bibliográfico, foram consultadas as bases de dados Scielo, Pubmed, Pepsic, LexisNexis, Bireme, Lilacs, PsycNet, PsycInfo, e Wiley Online Library. Foram usados os descritores: saúde, health, disorder, harm, risc, impairment, estresse, stress, burnout, ocupacional, occupational, qualidade, vida, resiliência, resilience, juiz(s), judge(s), magistrado(s), magistrate(s), justice e bench.

A produção nacional está limitada à publicação de três artigos, cujos dados serão apresentados a seguir. No cenário internacional, a contar do ano de 2000, foram encontrados nove artigos, sendo que em todos eles há a abordagem do estresse na vida dos magistrados.

\section{RELAÇÕES ENTRE ESTRESSE E PROBLEMAS DE SAÚDE DO MAGISTRADO BRASILEIRO}

No levantamento realizado, observa-se a prevalência de pesquisas brasileiras acerca do estresse nos magistrados, suas causas e efeitos, apesar de fatores como qualidade de vida e resiliência do trabalho também terem sido pesquisados. 
Na pesquisa de Lipp e Tanganelli (2002), 71\% dos profissionais pesquisados apresentaram sintomas significativos de estresse e perceberam sua profissão como uma das mais estressantes, semelhante aos trabalhadores de minas de carvão e pilotos de avião.

As mulheres apresentam nível de estresse maior do que os homens, pois aproximadamente $82 \%$ das juizas que participaram da pesquisa estavam na fase de resistência ${ }^{8}$ de estresse, enquanto $55,6 \%$ dos homens participantes da pesquisa estavam na mesma configuração.

A qualidade de vida foi identificada como um prejuizo acentuado nas áreas da saúde (com 78,7\% dos pesquisados com má qualidade de vida no respectivo âmbito) e da afetividade (com 41,3\% dos magistrados com índice de má qualidade de vida), sendo correlacionada, nos resultados da pesquisa, com alto nível de estresse detectado. A fonte de estresse mais citada na pesquisa foi o número excessivo de processos para julgar, enquanto que os sintomas de estresse mais encontrados foram: a sensação de desgaste e cansaço e a tensão muscular (Lipp \& Tanganelli, 2002).

$\mathrm{Na}$ pesquisa realizada com juízes de direito de Minas Gerais (Silva, 2005), conclui-se que as mudanças sociais, o avanço tecnológico e a globalização são fatores que contribuem para o acúmulo de trabalho dos judicantes, podendo desencadear o estresse.

A mobilidade, as promoções durante a carreira, as funções administrativas e o primeiro ano de exercício profissional são situações sentidas como estressantes pelos Magistrados. Um dado de extrema relevância, resultado da pesquisa de Silva (2005), é que o número de dias de afastamentos do trabalho, devido a licenças médicas, sugeriu um alto grau de adoecimento na população pesquisada.

\footnotetext{
8 A fase de resistência é intermediária ao processo de estresse, não está na fase de exaustão (nível mais elevado do estresse), mas não é somente a fase de alerta (a reação natural adaptativa aos fatores estressores em que há baixo índice de estresse). A fase é caracterizada pelo cansaço físico e mental, capacidade de memória comprometida e uma maior vulnerabilidade do sistema imunológico a doenças, notadamente as infecciosas (Lipp \& Tanganelli, 2002).
} 
Em pesquisa mais a respeito de resiliência e controle de estresse, realizada com juízes e servidores públicos, Oliveira e Lipp, (2009) constataram que o índice de estresse é maior nos pesquisados do que se costuma encontrar na população em geral. Concluíram pela incidência de estresse, com sintomas psicológicos, em $72 \%$ da população pesquisada, especialmente nas mulheres. No que diz respeito à fase do estresse, $74 \%$ das mulheres e 93\% dos homens estavam na fase resistência, sendo que $22 \%$ delas estavam na fase de quase exaustão e somente $2 \%$ deles apresentavam tais níveis de estresse.

Com relação às fontes de estresse, foram elencados quatro fatores estressores: número excessivo de feitos a julgar (assinalado por $96 \%$ dos juízes participantes da pesquisa); salários que não correspondem às responsabilidades, ao desgaste e à importância do cargo (95\%); falta de tempo para atualização (93\%); e sacrifício do tempo dedicado à vida familiar e social (92\%).

A preponderância da sobrecarga de processos, assim como da carga de trabalho, mantém-se em relação aos fatores elencados por Lazarus e Lazarus (1994). Nas mulheres, o fator estressor de destaque apontado é a dificuldade em conciliar as responsabilidades profissionais e familiares, seguida pelo excesso de trabalho e pela preocupação com a saúde e proteção dos filhos, dentre outros fatores.

Os homens apresentam maior frequência de comportamentos resilientes do que as mulheres. Foram identificadas ainda características de pessoas com menor risco de desenvolver estresse crônico (proveniente da fase de exaustão), que são pessoas que utilizam estratégias de enfrentamento no seu cotidiano, as estratégias levantadas na pesquisa foram: conversar com o cônjuge ou alguém com ligação afetiva (69\% disseram utilizar esta estratégia), pensar nos filhos (36\%, a segunda escolhida entre os casados) e passear (53\%, a segunda entre os solteiros). A grande maioria (73\%) não tem ou nunca teve acesso a processo de atendimento psicoterápico, que é também uma estratégia possível de enfrentamento. 
A regulação emocional foi apontada como o fator de proteção mais influente. As pessoas não estressadas afirmaram que o repertório eficaz de enfrentamento de adversidades é aprendido ao longo de sua história de vida (Oliveira \& Lipp 2009).

Por fim, em relação à análise das pesquisas no cenário brasileiro, Assunção (2011) está desenvolvendo, pela Universidade Federal de Minas Gerais, uma pesquisa com os magistrados trabalhistas brasileiros, para aferição das condições de saúde e de exercício profissional. Nos primeiros resultados já divulgados, as respostas convergem para uma situação de trabalho intenso, demonstrando que $84,4 \%$ dos magistrados trabalham em casa. Sendo que $64,3 \%$ declararam trabalhar durante as férias e 70,4\%, nos finais de semana, configurando invasão da vida extratrabalho. Nos últimos 12 meses do período pesquisado, 33,2\% tiraram licença médica e nos últimos 30 dias, 26\% deixaram de realizar tarefas habituais por problemas de saúde.

No âmbito dos problemas de saúde, a proporção de magistrados que relatam situações de obesidade, comprometimentos cardíacos, hipertensão e depressão (clinicamente diagnosticada) é maior do que a da população em geral. A proporção de $6,9 \%$ dos magistrados informa que seu estado de saúde é ruim, enquanto apenas $1,5 \%$ da população em geral apresenta a mesma resposta. Remédios para depressão e ansiedade são utilizados por $17,5 \%$ dos juízes, índice maior do que agentes comunitários de saúde, médicos e bombeiros de Belo Horizonte, índice superado apenas pelos funcionários do administrativo do corpo de bombeiros de Belo Horizonte, em que 18,6\% dos respondentes utilizam dos remédios controlados (Assunção, 2011).

Na pesquisa de Assunção (2011), a consistência interna do estudo foi confirmada pela síntese das respostas acerca da saúde e qualidade de vida, pois dentre os juízes respondentes, $41 \%$ sofrem depressão, 17,5\% utilizam medicamentos para depressão ou ansiedade, 53,8\% dormem mal, 37,8\% estão tristes atualmente, $15,1 \%$ têm chorado mais do que de costume e 50,9\% são vítimas frequentes, ou muito frequentes, de insônia. $\mathrm{O}$ estudo 
aponta ainda que os juízes usam proporcionalmente mais remédios para alterações de sono, diabetes, reumatismo, hipertensão e "outros", do que as demais profissões pesquisadas na mesma época em Belo Horizonte, que são: profissionais administrativos do setor da saúde, agentes comunitários de saúde, médicos e membros do corpo de bombeiros.

Os dados ainda dependem de um processo de análise para identificação do impacto das propriedades que caracterizam o exercício da atividade judicante em seu contexto ambiental e organizacional sobre o estado e os hábitos de saúde dos respondentes (numa e noutra direção).

Apesar de pouco numerosas, as pesquisas conseguem traçar um perfil acerca da saúde do juiz brasileiro, de suas condições de trabalho e do funcionamento interno do Poder Judiciário. Nos resultados encontrados, constata-se a incidência de altos níveis de estresse na população pesquisada, bem como comprometimento da qualidade de vida.

\section{RELAÇÕES ENTRE ESTRESSE, BURNOUT E VICARIOUS: TRAUMA NO CONTEXTO LABORAL DO MAGISTRADO NO MUNDO}

No contexto internacional, como se verá a seguir, todas as pesquisas são relacionadas ao estresse na vida do magistrado.

Com ênfase no estresse laboral, Chase e Hora (2000) apontam que esse é o foco mais comum das pesquisas de satisfação de trabalho com juízes. Os fatores mais indicados como causadores do estresse, segundo pesquisas realizadas na década de 80 são: o isolamento social; o sentimento de não afirmação social; a falta de interesse e de compreensão; a sensação de não serem apreciados. A falta de feedback, o excesso de trabalho e a consequente falta de controle de todos os processos que aguardam julgamento, a frustração com a própria falta de habilidade para ajudar os litigantes são também referidos como fatores causadores de estresse (Chase e Hora, 2000). 
Chase e Hora (2000) realizaram pesquisa comparativa do nível de ocorrência de estresse laboral e satisfação no trabalho com juízes que judicam em cortes de jurisprudência terapêutica, em relação àqueles que trabalham em varas de família.

Cortes de jurisprudência terapêutica são aquelas que encaminham dependentes químicos para tratamento de saúde, com apoio de equipe multidisciplinar, objetivando afastá-los do crime. A pesquisa demonstra que os juízes destas cortes, acompanhando significativas recuperações na vida das pessoas que se saem bem no programa, reconhecem em si mesmos sintomas de alcoolismo, param de fumar e beber e adquirem hábitos saudáveis. Outra característica das cortes terapêuticas é que o juiz e a sua equipe têm contato com o réu e seus familiares durante todo o tratamento. Em consequência, encontram-se evidências de crescimento da satisfação com o trabalho e com a saúde mental e, por haver mais propriedade em suas decisões, o resultado é que o nível de estresse não é tão elevado neste contexto (Chase e Hora, 2000).

Porém, no âmbito das varas de família, o estresse laboral é mais percebido, relatando os magistrados, com maior ênfase, os fatores mais indicados como causadores do estresse acima listados. A pesquisa aponta que tais sintomas decorrem da frustração enfrentada no trabalho diário, já que diversos problemas de uma mesma família tramitam em cortes diferentes, impedindo o acompanhamento global da família por um único juiz. Em consequência, não há o mesmo envolvimento emocional com o réu e seus familiares, como nas cortes de recuperação, não provocando nos magistrados os mesmos níveis de satisfação com o trabalho (Chase e Hora, 2000).

Em outra pesquisa analisada, Bremer (2002) constatou a possibilidade de redução do estresse ocupacional, o qual se manifesta em tensão física e mental, quando novos juízes recebem orientação de outros mais experientes. Sua pesquisa demonstrou a eficácia de um programa de orientação, na melhora do estresse e tensão, bem como aumento nas habilidades de enfrentamento. 
As pesquisas evidenciam que o juiz é submetido a uma expressiva carga de estresse, apontando a necessidade de atentar-se aos riscos a que está sendo submetido, buscando-se formas de proteção à sua saúde.

Também no contexto internacional, é possível perceber, no mesmo período, pesquisas acerca da ocorrência de burnout, além do estresse, entre os magistrados. Surge ainda a ocorrência de Vicarious Trauma em juízes foi pesquisada por Jaffe et al. (2003) e aparece novamente como objeto de pesquisa, na publicação de Chamberlain et al. (2009) e em Resnick et al. (2011).

Vicarious Trauma diz respeito ao desenvolvimento, pelo profissional que trabalha com pessoas que sofreram grandes traumas, dos mesmos sintomas experimentados por estas. Além da incidência de pesquisas sobre o estresse no contexto laboral, a ocorrência de Vicarious Trauma em juízes também foi constatada em pesquisa realizada nos EUA (Jaffe et al., 2003). Dos juízes pesquisados, as juízas (73\%), mais do que os juízes (54\%), apontaram a presença de um ou mais sintomas do trauma.

Entre os sintomas destacados pelos autores, destacam-se: dificuldades interpessoais, como a falta de empatia e a intolerância com as pessoas; angústia emocional (como depressão, sensação de isolamento); sintomas físicos (como insônia, perda de apetite); sintomas cognitivos (dificuldade de concentração) e; diagnósticos atuais (por exemplo PSD) (Jaffe et al., 2003).

$\mathrm{Na}$ verificação dos sintomas do trauma e o tempo de carreira, verifica-se que começam a aparecer em torno do sétimo ano. Realizou-se uma divisão em dois grupos: juízes que estavam iniciando e tinham até seis anos de carreira, e com sete anos ou mais. Juízes com mais de seis anos de carreira apresentavam um ou mais sintomas de Vicarious Trauma, enquanto que os juízes mais experientes apresentavam uma variedade maior de sintomas (Jaffe et al., 2003).

As estratégias de enfrentamento para lidar com esses sintomas de Vicarious Trauma foram divididas em três categorias: pessoais, profissionais e sociais. Não houve diferença com 
respeito ao número de estratégias entre homens e mulheres, mas a maioria opta pelas de cunho pessoal. $73 \%$ dos juízes apontaram pelo menos uma estratégia de prevenção e elas visam alcançar um equilíbrio entre o trabalho e a vida pessoal, desenvolvendo filosofias saudáveis e mantendo o bom humor (Jaffe et al., 2003).

Anleu \& Mack (2005) classificam como trabalho emocional, aquele em que o gerenciamento constante das emoções é parte do desempenho profissional. Os juízes frequentemente regulam suas emoções ao trabalharem frente à frente com pessoas que nem sempre estão representadas por advogados ou defensores, e expressam suas emoções como raiva e angústia, extraindo respostas emocionais dos magistrados. Nas cortes superiores, todos estes sentimentos são mitigados pelo filtro obrigatório da presença dos representantes das partes, mas na primeira instância as emoções, frequentemente negativas, são constantes (Anleu \& Mack, 2005).

O conjunto das cortes configuram o local dramaticamente simbólico onde interagem a lei e a sociedade, e o gerenciamento das emoções passa a ser o eixo que os liga. Em decorrência, $66 \%$ dos juízes que participaram da pesquisa, consideraram muito importante a gestão das emoções dos jurisdicionados no seu trabalho diário. $\mathrm{O}$ trabalho do juiz de primeira instância cumpre todos os requisitos e se encaixa no conceito de trabalho emocional. Um fato que pode causar uma possível gênese de risco, é que este tipo de trabalho está associado à ocorrência de estresse, burnout e exaustão, além de minar o senso de profissionalismo (Anleu \& Mack, 2005).

$\mathrm{Na}$ outra pesquisa apontada, Lustig et al. (2008), constataram altíssimos níveis de estresse e burnout, ao pesquisar juízes que trabalham nas cortes de imigração. Os autores concluíram que o trabalho diário com horríveis histórias de sofrimento humano, acarretaram comprometimentos na saúde do magistrado. Quem foi ou possa vir a ser vítima de perseguição política, busca nas cortes de imigração o direito ao asilo. Para tanto, 
o juiz ouve diuturnamente as narrativas, por parte das vítimas, das atrocidades a que foram submetidas. As decisões, nestes casos, são relativas a quem será deportado e quem permanecerá em solo americano. Uma deportação pode ser equivalente a uma sentença de morte (Lustig et al., 2008).

A pesquisa demonstrou fortes associações entre burnout e subsequentes faltas ao trabalho, decorrentes de problemas de saúde dos magistrados. Os pesquisados apontam que os dados referentes aos índices de burnout são elevados e, mesmo sem apresentar números para a constatação, os autores afirmam que o índice de burnout nos juízes ultrapassa os índices de médicos de hospitais lotados e agentes prisionais, aparecendo as mulheres como mais afetadas do que os homens nos sintomas (Lustig et al., 2008).

Além do burnout, o Estresse Traumático Secundário (incluindo Vicarious Trauma) e a preocupação com a segurança entre juízes de uma mesma jurisdição, foram tema de pesquisa de Chamberlain e Miller (2009), nos EUA. Os resultados demonstraram que, apesar de nenhum juiz ter apresentado sintomas extremos, todos tinham sintomas associados com estresse traumático secundário, preocupações com segurança e/ou burnout (Chambelain et al, 2009). Os resultados da pesquisa apontam para a vulnerabilidade dos juízes ao Estresse Traumático Secundário, por estarem constantemente expostos ao trauma de outrem e por sentirem empatia pelas vítimas.

Preocupações com segurança, decorrentes de atos de violência e ameaças contra juízes e seus familiares, também contribuem com o estresse laboral, ou estresse judicial (Chambelain et al, 2009). A violência contra os juízes acarreta um senso de vulnerabilidade e insegurança para qualquer um que assuma a toga. As evidências de burnout apareceram em muitos juízes pesquisados que apresentavam, por exemplo, conflitos no local de trabalho e sobrecarga de responsabilidades. Embora nenhum juiz pesquisado tenha apresentado sintomas extremos, todos eles apresentaram sintomas leves de estresse traumático secundário, preocupações com segurança e burnout. 
Ciocoiu, Cojocaru e Ciocoiu, publicaram, em 2010, uma pesquisa acerca da ocorrência de estresse em magistrados romenos. Foi feita uma observação direta de seus locais e condições de trabalho, bem como discussões com as pessoas envolvidas com o trabalho da magistratura. Como resultado da pesquisa, os autores afirmaram que há incidência de estresse em pelo menos $25 \%$ da amostra, e apontam a necessidade de novas pesquisas.

Flores et al. (2010) pesquisaram a respeito das perspectivas dos juízes acerca de estresse e segurança nas cortes onde trabalham e a preocupação com a segurança dos jurados que participavam dos julgamentos. 40,2\% relataram ter tido experiências de estresse/satisfação, ao responderem afirmativamente a questão: "no ano passado, você experimentou alguma experiência no trabalho que lhe causou estresse (e.g., algum evento violento ou ameaçador)?". Os resultados demonstraram que os juízes sentem-se responsáveis pela segurança dos jurados e pelo estresse neles causado, usando aproximadamente 10 estratégias diferentes para diminuí-lo. A pesquisa aponta que os membros do judiciário são suscetíveis ao estresse ocupacional. Três medições separadas foram realizadas, apontando estresse em geral e durante os julgamentos, além de sintomas físicos e emocionais.

Por fim, Perales et al. (2011) pesquisaram os juízes atuantes em Lima, Peru. Os autores constataram que um quarto da magistratura apresenta quadro de estresse, ansiedade ou depressão. Este é um dado significativo e aponta para a possibilidade de ampliação dos estudos sobre quais os fatores que acarretam sintomas e adoecimentos vivenciados pelos magistrados na sua ocupação laboral. É uma possibilidade levantada pelos autores, de que o contexto das atividades laborais dos magistrados sejam acompanhadas por demandas e situações estressoras, em detrimento de outros tipos de atividades e outros cargos laborais.

\section{CONCLUSÃO}

Em consideração às pesquisas apresentadas, foi possível identificar que, na última década, somente quatro estudos foram 
realizados no Brasil acerca da vida e da saúde do magistrado. Os resultados apontam para o comprometimento da qualidade de vida, ocorrência de estresse e Síndrome de burnout acima dos níveis da população em geral. Pesquisas recentes demonstram que os serviços humanos, dentre eles o judicial, acarretam mais insatisfação do que o trabalho realizado em escritórios. Os profissionais podem se sentir mais abalados do que as pessoas que atendem, sendo comum o sentimento de impotência frente à burocracia que inviabiliza que se atinjam resultados perseguidos (Assunção, 2011). Conclui-se, portanto, pela necessidade de novas e mais aprofundadas pesquisas na área, para um melhor desenvolvimento da identificação dos fatores de risco e de proteção ao magistrado.

As causas, concausas e consequências do estresse podem ser oriundas de três fatores: pessoais (como o gênero, conflitos no âmbito dos desejos e afetos, nas ambiguidades presentes nas relações interpessoais), de trabalho (como a impossibilidade de cometer erros ou equívocos ou o número expressivo de julgamentos estressantes) e de características ambientais (ciência de atentados violentos a outros juízes, precariedade nos serviços das varas e falta de suporte de outros profissionais).

No levantamento bibliográfico realizado, considerando a abordagem do estresse, além deste e do burnout, constatou-se a ocorrência da síndrome de Vicarious Trauma, que é um adoecimento pela empatia, por uma vivência anterior com um terceiro que já teve os sintomas ou mesmo a síndrome. Portanto, pode-se levantar a possibilidade de que os magistrados que sentem empatia pelas pessoas envolvidas em sua decisão, acabam expostos a uma situação estressora, ou de sintomas efetivamente presentes.

Por fim, é possível concluir que uma decisão tomada por um magistrado que esteja com problemas em sua saúde, sofrendo qualquer tipo de ameaça ou com sentimentos de ameaça, pode trazer reflexos negativos ao julgamento do caso e a todo o sistema de justiça, já que um juiz doente ou amedron- 
tado não conseguirá julgar com a tranquilidade e a imparcialidade necessárias, o que poderá enfraquecer o sistema judicial.

\begin{abstract}
Through a bibliographical survey, this study indicates research on the health of judges, from the viewpoint of the complexity of the relation between people and work, since these relations have led researchers to investigate the reflections on the health of workers. The research presents data on the work of judges, principally from a standpoint of stress.
\end{abstract}

Keywords: Health. Judges. Stress.

\title{
REFERÊNCIAS
}

Anleu, S. R., \& Mack, K. (2005). Magistrates' Everyday Work and Emotional Labour. Journal of Law and Society, vol.32 Issue 04.

Assunção, A. (2011). Situações de saúde e condições do exercício profissional dos magistrados trabalhistas do Brasil - Primeiros resultados. Faculdade de Medicina. UFMG. Brasília, DF, Brasil. Recuperado em 18 de dezembro, 2011, de http://ww1.anamatra.org.br/ sites/1200/1223/00002920.pdf

Bremer, C. F. (2002). Impact of a Mentoring Program on occupational stress, personal strain and coping resources of newly appointed U.S. Magistrate Judges. Tese de doutorado. EEUU: Drake University, School of Education. Des Moines, Iowa, EUA.

Borsoi, I. C. F. (2007). Da relação entre trabalho e saúde à relação entre trabalho e saúde mental. Psicologia $\mathbb{E}$ Sociedade, 19(1), 103-111.

Chamberlain, J., \& Miller, M. (2009). Evidence of Secondary Traumatic Stress, Safety Concerns, and Burnout Among a Homogeneous Group of Judges in a Single Jurisdiction. Journal of the American Academy of Psychiatry and the Law Online. 37(2). 214-224. Recuperada em 20 de setembro, 2012, de http://www.jaapl.org/content/37/2/214.full.pdf + html

Chase, D., \& Hora, P. F. (2000). The Implications of Therapeutic Jurisprudence for Judicial Satisfaction. Court Review. Recuperado em 14 de dezembro, 2011, de http://www.ncsconline.org/wc/publications/Res JudEdu SubstanceAbuseMaterial12Pub.pdf

Ciocoiu, M., Cojocaru M., \& Ciocoiu, S. V. (2010). Stress Related Manifestations Regarding Magistrates. Romanian Biotechnological Letters. 
15(3) 135- 141. Recuperado em 14 de dezembro, 2011, em http://ebooks. unibuc.ro/biologie/RBL/rbl3vol15Supplement/19.\%20Articol\%20 Ciocoiu\%20Monica\%202.pdf

Codo, W., \& Vasques-Menezes, I. (1999). Burnout: Síndrome da desistência. In W. Codo (Ed.), Educação: Carinho e trabalho (pp. 237-255). Petrópolis, RJ: Vozes.

Constituição da República Federativa do Brasil de 1988. (2001). [Coleção Saraiva de legislação]. (21a ed.). São Paulo: Saraiva. Brasil.

Dejours, C. (1992). A loucura do trabalho: Estudo de psicopatologia do trabalho. São Paulo, SP: Cortez/Oboré. Dejours, C. (1994). A carga psíquica do trabalho. In C. Dejours, E. Abdoucheli, \& . Jayet. Psicodinâmica do trabalho: Contribuições da escola dejouriana à análise da relação prazer, sofrimento e trabalho (pp. 21-32). São Paulo, SP: Atlas

Flores, D. M., Miller, K. M., Chamberlain, J., Richardson, J. T., \& Bornstein, B. H. (2010). Judges' Perspectives on Stress and Safety in the Courtroom: An Exploratory Study. Court review. Recuperado em 14 de dezembro, 2011, de http://aja.ncsc.dni.us/publications/courtrv/cr45-3/ CR45-3Flores.pdf

Jacques, M. G. (2003b). "Doença dos nervos”: uma expressão da relação entre saúde/doença mental. In : Jacques, M. G. ; Codo, W. (orgs) Saúde mental $\mathcal{E}$ trabalho; leituras. p. 98-111. Petrópolis, RJ, Brasil: Vozes.

Jaffe, P. G., Crooks, C. V., Dunford-Jackson, B. L., \& Town, J. M. (2003). Vicarious Trauma em juízes. Juvenile and Family Court Journal. Recuperado em 14 de dezembro, 2011, de http://www.crvawc.ca/documents/Vicarious Trauma Judges Fall03.pdf

Lazarus, R. S., \& Lazarus, B. N. (1994). Passion and reason: making sense of our emotions. New York: Oxford University Press.

Lipp, M., \& Tanganelli M. S. (2002). Stress e Qualidade de Vida em Magistrados da Justiça do Trabalho: Diferenças entre Homens e Mulheres. Psicol. Reflex. Crit. 15(3)

Lustig, S. M., Delucchi, K., Tennakoon, L., Kaul, B., Marks, D. L., \& Slavin, J. D. (2008). Burnout and Stress Among United States Immigration Judges. Bender's Immigration Bulletin. Recuperado em 14 de dezembro, 2011, de http://pdfserver.amlaw.com/nlj/ImmigrJudgeStressBurnout.pdf

Maslach, C., \& Jackson, S.E. (1981). The measurement of experienced Burnout. Journal of Ocuppational Behavior. 2(2), p. 99-113. San Francisco, California, EUA. 
Maslach, C., \& Leiter, M. P. The truth about burnout: How organization cause, personal stress and what to do about It. San Francisco, California, EUA: Jossey-Bass, 1997.

Munhoz, J. L. (2012). http://www.espacovital.com.br/noticia-28949. sentenca-nao-em-arvore-artigo-jose-lucio-munhoz

Oliveira, J. B., \& Lipp M. (2009). Resiliência e controle do stress em juízes e servidores públicos. Boletim Academia Paulista de Psicologia, 77 (2), 2009.

Perales, Chue, Padilla, Barahona, (2011) Estrés, ansiedad y depresión en magistrados de Lima, Perú. Rev. perú. med. exp. salud publica. 28(4) p.581588. Recuperado em 12 de dezembro, 2011, http://www.scielo.org.pe/ scielo.php?script $=$ sci_arttext $\&$ pid $=\$ 1726-46342011000400002 \& \operatorname{lng}=\mathrm{es} \& \mathrm{nr}$ $\mathrm{m}=\mathrm{iso}>$. ISSN 1726-4634.

Resnick, A., Myatt K. A., Marotta P. V. (2011). Surviving bench stress. Family Court Review. 49(3), p. 610-7. Recuperado em 14 de dezembro, 2012, em http://onlinelibrary.wiley.com/doi/10.1111/j.1744-1617.2011.01396.x/abstract

ROCHA, Lys Esther; NUNES, Everardo Duarte. Saúde e Trabalho no Brasil - Porque retornar os caminhos da história. In: ROCHA, Lys Esther; RIGOTTO, Raquel; BUSCHINELLI, José Tarcísio (orgs). Isto é trabalho de gente? Vida, doença e trabalho no Brasil. São Paulo:Vozes, 1993, p. 79-82.

Sampaio, J. J. C., \& Messias, E. L. M. (2002). A epidemiologia em saúde mental e trabalho. In M. da G. Jacques \& W. Codo (Eds.), Saúde mental e trabalho: Leituras (pp. 143-171). Petrópolis, RJ: Vozes

Santa H. E., Lasagno, B., Vieira, R. (2010). Prevalência de transtornos mentais não-psicóticos e fatores associados em pessoas com hipertensão arterial sistêmica e/ou diabetes mellitus em Unidades de Saúde da Família em Blumenau, Santa Catarina. Revista Brasileira de Medicina Familiar e Comunitária. 5(17), p. 42-47. Florianópolis, SC, Brasil.

Silva, M. J. da. (2005). Fatores Desencadeadores de Estresse nos Magistrados: o Caso de Minas Gerais. MG, Brasil.

Teixeira, S. (2007). A depressão no meio ambiente do trabalho e sua caracterização como doença do trabalho. Revista do Tribunal Regional do Trabalho da $3^{a}$ Região, 46(76), p.27-44. Belo Horizonte, MG, Brasil. Recuperado em 21 de setembro, 2012, de http://www.trt3.jus.br/escola/ download/revista/rev 76/Sueli Teixeira.pdf

Vasques-Menezes, I. (2004). Por onde passa a categoria trabalho na prática terapêutica? In W. Codo (Ed.), O trabalho enlouquece?- Um encontro entre a clínica e o trabalho (pp. 23-32). Petrópolis, RJ: Vozes.

Zimmerman, I. M. (1981). Stress: What it does to judges and how it can be lessened. Judges Journal, 4, p. 18-22. 